\title{
Specimen size and shape effects on strength of concrete in the absence and presence of steel fibers
}

\author{
Ali Mardani-Aghabaglou (Main and Corresponding Author) \\ Bursa Uludag University \\ 16000, Bursa (Turkey) \\ alimardani@uludag.edu.tr
}

Sultan Husein Bayqra

Bursa Uludag University

16000, Bursa (Turkey)

sultanhuseinbayqra@yahoo.com

Amir Nobakhtjoo

Istanbul Technical University

16000, Bursa (Turkey)

nobakhtjoo.amir@gmail.com

Manuscript Code: 15450

Date of Acceptance/Reception: 21.03.2021/17.06.2020

DOI: 10.7764/RDLC.20.1.128

\begin{abstract}
In this research, the effects of size and shape on compressive and splitting tensile strength of fibrous and non-fibrous concrete specimens with different characteristic strength were investigated. With this aim, both fibrous and non-fibrous 10 different concrete mixtures with $0.3,0.4,0.5,0.6$ and 0.7 Water/Cement ratio were prepared. In the fibrous mixture specimens, the total amount of steel fibers to $1 \%$ by total volume. In the entire specimens, $42.5 \mathrm{R}$ type Portland cement were used as bonding elements while crushed lime stones in 3 sizes were added to the mixtures. Furthermore, to evaluate the influence of size and shapes over specimens' strength, for each concrete mixtures two $10 \mathrm{~cm}$ and $15 \mathrm{~cm}$ cubic specimen beside two $10 \times 20 \mathrm{~cm}$ and $15 \times 30 \mathrm{~cm}$ cylindrical specimens were prepared as well. The prepared specimens were subjected to compressive and splitting tensile tests. The results showed that, regardless of the fiber amount and specimens' shapes, the decrease in specimens' size resulted in higher strength. But in the high ratio of Water/Cement and fibrous mixtures, the mentioned behavior was not observed.
\end{abstract}

Keywords: shape effect, size effect, steel-reinforced concrete, splitting tensile strength, compressive strength.

\section{Introduction}

The fact that the concrete holds heterogenic texture results in different stress values in the case of loading as a result of hydration and hardening of its components. Due to the external and internal effects, significant stresses occur especially on the aggregate-cement paste interface (transition zone), known as the weakest part of the concrete (Mardani-Aghabaglou et al., 2019). These stresses result in cracks on the aggregate-cement paste surface. Along with the effects of external stresses, these cracks grow and affect the mechanical properties and stress-strain behavior of the concrete negatively. One of the most preferred methods to improve these properties in concrete is the addition of steel fiber in concrete mixtures (Alex \& Arunachalam, 2019; Ouedraogo et al., 2021). These randomly distributed fibers increase the occupancy and limit the cracks at different stages of the concrete, preventing their growth and distribution of the internal stresses. These favorable effect of the fibers alter the fracture behavior of the concrete after maximum load positively. The effectiveness of the steel fibers used in concrete might change in accordance with fiber geometric structure, fiber type, aspect ratio, tensile strength, and volume (Köroglu \& Ashour, 2019; Zeynal, 2008).

As it is known, compressive and tensile strengths are two important parameters for defining the mechanical properties of the concrete. The checking of compressive strength of concrete is commonly essential during the structural design. Besides, controlling of the tensile strength is important in particular structures such as earthquake resistant structures, airstrip, and pavement. The compressive strengths of the standard cylinder and cube specimens $(15 \times 30 \mathrm{~cm}, 15 \mathrm{~cm})$ can be considered as common feature used in concrete quality control. As a known fact that the compressive strength of concrete varies according to the shape and size of the concrete specimens. The shape and size of the specimens used to determine the strength of concrete are not the same in every country; however, the most preferred are cube and cylinder specimens. That is, cube specimens $(15 \mathrm{~cm})$ are used in Germany, UK and many other European countries while cylinder specimens $(15 \times 30 \mathrm{~cm})$ are used in the USA, Canada, South Korea, Australia and France. Also, both cylinder and cube specimens are used in many countries (e.g. Norway). Cylinder and cube strengths obtained from the same concrete mixer may differ due to specimens' shape and size (Yi et al., 2006). 
It is commonly known that the cube specimens show higher compressive strength than the cylindrical specimens because of their end effects (Aslani, 2013; Felekoğlu \& Türkel, 2005). However, some researchers reported that the strength difference is less in high-strength concretes (Yi et al., 2006). Many studies in this field have been conducted since the early 1900s (Aitcin et al., 1994; Neville A.M, 1996; Tokyay \& Özdemir, 1997; Che et al., 2011; Dehestani et al., 2014; Li et al., 2018; Khalilpour \& Dehestani, 2021; Zhang et al., 2021). Many researchers have tried to develop a suggestion to convert non-standard concrete specimens to standard specimens. The relation between the strength of cylinder and cube specimens were investigated in many studies (Gyurkó \& Nemes, 2020; Li et al., 2018). It is a common use that the strength of the cylinder specimen to be multiplied by a coefficient of 1.2 in order to be converted into the cube specimen strength. However, this coefficient decreases with increasing concrete strength. According to fib $M C$ 2010 (CEB-FIP MC10, 2010) increasing the compressive strength of concrete causes the cube-cylinder strength ratio to decrease gradually from 1.25 to 1.15 . While 1.25 ratio has $40 \mathrm{MPa}$ cylinder compressive strength and 1.15 ratio corresponds to $100 \mathrm{MPa}$.

Del Viso et al., (2008) investigated the effects of the size and shape of the cylindrical and cube specimens at different sizes on the compressive strength of high strength concrete. As a result, it has seen that the small specimens showed high compressive strengths. The size effect was reported to be less in cylinder specimens than in cube specimens. (Dehestani et al., (2014) in their study on self-consolidating concrete (SCC), investigated the effects of specimen size and shape on the compressive strength. Cylinder and cube specimens were used in the study. Regardless of the aspect ratio, it was found that the concrete strength decreased as the specimen size increased and the decrease was more obvious in the specimens with low aspect ratio. Strength ratio decrease for the cylindrical specimens were observed with the decrease of the aspect ratio. According to these results, the specimen size was found to be more distinct in specimens with low aspect ratio. It was stated that the decrease in strength ratio at stable aspect ratio is mostly dependent on the mixing ratios, especially the $\mathrm{W} / \mathrm{C}$ ratio of the mixture.

It was also described that the specimen size is even more distinct in low strength concretes. It was found that the specimen size effect at high aspect ratios (h / d) became independent from water cement ratio. Moreover, the cube specimens showed higher strength than cylindrical specimens when the slenderness ratios are the same. (Gyurkó \& Nemes, (2020) examined the effect of sample size and shape on the compressive strength of normal strength concrete. The results showed that the size effect was stronger in low-strength concretes due to the mixtures' inhomogeneity. It was also explained that the size effect was more pronounced in cubic samples than in cylindrical samples.

\section{Novelty, scope, and significance}

As a result of the conducted researches, it can be stated that the effect of specimen's shape and size on concrete strength has been investigated. These studies revealed different correlation coefficients on specimens' shape and size. However, it has been determined that there is a lack of studies to investigate the effect of sample shape and size in fiber concretes with different $\mathrm{W} / \mathrm{C}$ ratios and to establish correlation coefficients between these samples. This study investigates the effect of sample shape and size on the strength of steel fibrous concretes with different $\mathrm{W} / \mathrm{C}$ ratios. For this purpose, fibrous and non-fibrous concrete mixtures with five different $\mathrm{W} / \mathrm{C}$ ratios, $0.3,0.4,0.5,0.6$ and 0.7 , were produced. In fibrous mixtures, $1 \%$ steel fiber with an aspect ratio of 64 the total volume was used. To determine the specimen shape and size effects on concrete strength, $10 \mathrm{~cm}$ and $15 \mathrm{~cm}$ cube specimens, $10 \times 20 \mathrm{~cm}$, and $15 \times 30 \mathrm{~cm}$ cylinder specimens were prepared. Thus, 480 cylindrical and cubic specimens were produced in total and strength-time and strength-specimen size and shape relationships were compared in fibrous and non-fibrous concretes with different strength classes. 


\section{Materials and methods}

In this part, the chemical and physical properties of the materials used in the experimental study and the amounts of materials used for the production of $1 \mathrm{~m}^{3}$ concrete are demonstrated. In order to minimize the effect of the ambient conditions on the experiment, all the materials which are used in the study were kept in a room with a temperature of $20 \pm 2{ }^{\circ} \mathrm{C}$ for 48 hours before the experiment.

\section{Cement}

In the experimental studies, CEM I 42.5R type cement produced by Bursa cement factory with $3530 \mathrm{~cm}^{3} / \mathrm{g}$ of specific surface and 3.15 of specific weight, respectively, were used in accordance with TS EN 197-1 (TS EN 197-1, 2012) Standard. The mechanical, physical and chemical properties of the cement used are given in Table 1.

Table 1.Chemical composition and mechanical and physical properties of the cement. (Self-Elaboration).

\begin{tabular}{|c|c|c|c|c|}
\hline Item & $(\%)$ & \multicolumn{3}{|c|}{ Physical Properties } \\
\hline $\mathrm{SiO}^{2}$ & 18.86 & \multicolumn{2}{|c|}{ Specific Gravity } & 3.15 \\
\hline $\mathrm{Al}^{2} \mathrm{O}^{3}$ & 5.71 & \multicolumn{3}{|c|}{ Mechanical Propierties } \\
\hline $\mathrm{Fe}^{2} \mathrm{O}^{3}$ & 3.09 & Compressive & 1-Day & 14.7 \\
\hline $\mathrm{CaO}$ & 62.70 & strength (MPa) & 2-Day & 26.80 \\
\hline MgO & 1.16 & & 7-Day & 49.80 \\
\hline $\mathrm{SO}^{3}$ & 2.39 & & 28-Day & 58.5 \\
\hline $\mathrm{Na} 2 \mathrm{O}+0.658 \mathrm{~K}_{2} \mathrm{O}$ & 0.92 & \multicolumn{3}{|c|}{ Fineness } \\
\hline $\mathrm{Cl}^{-}$ & 0.01 & \multicolumn{2}{|c|}{ Blaine Specific surface $\left(\mathrm{cm}^{2} / \mathrm{g}\right)$} & 3530 \\
\hline Insoluble residual & 0.32 & \multicolumn{2}{|c|}{ Residual on $0.045 \mathrm{~mm}$ sieve (\%) } & 7.6 \\
\hline Loss on ignition & 3.20 & & & \\
\hline Free $\mathrm{CaO}$ & 1.26 & & & \\
\hline
\end{tabular}

\section{Aggregates}

In concrete mixtures crushed limestone aggregate with the largest grain diameter of $22 \mathrm{~mm}$ was used. Water absorption capacity and specific gravity of aggregates obtained according to TS EN 1097-6 (TS EN 1097-6, 2013) Standard is given in Table 2. In addition, gradation of the aggregates shown in Table 3 was performed according to TS EN 206 (TS EN 206, 2014) Standard. In concrete mixtures, crushed limestone aggregate as $40 \%$ of total aggregate volume of $0-5 \mathrm{~mm}, 30 \%$ of $5-12 \mathrm{~mm}$ and $30 \%$ of $12-22 \mathrm{~mm}$ of size was used.

\begin{tabular}{|c|c|c|c|c|}
\hline \multicolumn{2}{|l|}{ Aggregate } & \multirow[b]{2}{*}{$\begin{array}{l}\text { Specific } \\
\text { Gravity }\end{array}$} & \multirow[b]{2}{*}{ Bulk Density $\left(\mathrm{kg} / \mathrm{m}^{3}\right)$} & \multirow[b]{2}{*}{$\begin{array}{l}\text { Water Absorption } \\
\text { Capacity (\%) }\end{array}$} \\
\hline Type & $\begin{array}{l}\text { Dimension } \\
(\mathrm{mm})\end{array}$ & & & \\
\hline \multirow{3}{*}{$\begin{array}{l}\text { Crushed } \\
\text { limestone }\end{array}$} & $0-5$ & 2.72 & 1655 & 0.80 \\
\hline & $5-12$ & 2.68 & 1441 & 0.44 \\
\hline & $12-22$ & 2.71 & 1405 & 0.24 \\
\hline Sieve siz & $(\mathrm{mm})$ & $0-5 \mathrm{~mm}$ & $5-12 \mathrm{~mm}$ & $12-22 \mathrm{~mm}$ \\
\hline & 31.5 & 100 & 100 & 100 \\
\hline & 16 & 100 & 100 & 49.7 \\
\hline & 8 & 100 & 72.2 & 0.1 \\
\hline & 4 & 100 & 7 & 0 \\
\hline & 2 & 77.5 & 0 & 0 \\
\hline & 1 & 49.3 & 0 & 0 \\
\hline & 0.5 & 32 & 0 & 0 \\
\hline & 0.25 & 12.9 & 0 & 0 \\
\hline & 0.125 & 2.5 & 0 & 0 \\
\hline
\end{tabular}




\section{Water reducing admixtures}

Polycarboxylate-ether based, high rate water reducing admixtures purchased from Polisan company were used in different ratios to provide the desired slump values in concrete mixtures. Some properties of the water reducing additives used by the manufacturer are shown in Table 4.

Table 4. Properties of the water reducing admixture. (Self-Elaboration).

\begin{tabular}{lcccc}
\hline & \multicolumn{2}{c}{ Table 4. Properties of the water reducing admixture. (Self-Elaboration). } \\
\hline Type & Density $\left(\mathrm{g} / \mathrm{cm}^{3}\right)$ & $\mathrm{pH}$ value & $\begin{array}{l}\text { Chloride } \\
\text { Content (\%) }\end{array}$ & $\begin{array}{l}\text { Alkali Content, } \\
\mathrm{Na}_{2} \mathrm{O}(\%)\end{array}$ \\
\hline $\begin{array}{l}\text { Polycarboxylate ether } \\
\text { based }\end{array}$ & $1.023-1.063$ & $5-8$ & $<0.1$ & $<10$ \\
\hline
\end{tabular}

\section{Steel fiber}

In fibrous mixtures, mono-type steel fiber with 64 aspect ratio and two hooks at both ends in accordance with TS EN 14889-1 (TS EN 14889-1, 2006) standard was used. Additionally, for all fibrous mixtures, the fiber utilization rate was kept constant at $1 \%$ of the total mixtures volume. The mechanical and physical properties of the used steel fibers are given in Table 5 .

\begin{tabular}{lc}
\multicolumn{2}{c}{ Table 5. Mechanical and physical properties of the steel fibers. (Self-Elaboration). } \\
\hline Lenght $(\mathrm{mm})$ & 35 \\
\hline Diameter $(\mathrm{mm})$ & 0.55 \\
\hline Density $\left(\mathrm{g} / \mathrm{cm}^{3}\right)$ & 7.8 \\
\hline Aspect ratio & 64 \\
\hline Tensile strength $\left(\mathrm{N} / \mathrm{mm}^{2}\right)$ & 1500 \\
\hline
\end{tabular}

\section{Preparation of the mixtures}

As previously mentioned, a set of 10 mixtures with and without fibers were produced within the extent of the study. The slump value was kept constant at $17 \pm 2 \mathrm{~cm}$ in all mixtures. The slump test was performed according to the TS EN 12350-2 (TS EN 12350-2, 2010) standard. High water reducing admixture was used in different ratios to provide requested slump value. The material quantities for $1 \mathrm{~m} 3$ of concrete production are given in Table 6 . As a result, the water reducing admixture requirement has increased with the use of fiber in order to achieve the requested slump value $(17 \pm 2 \mathrm{~cm})$. This was more distinct in concrete with low W/C ratios. As expected, the fresh state unit weight of concrete mixtures increased slightly with the use of fiber. Concrete mixtures prepared in the mixer were placed in the molds by compaction according to the relevant standard. The produced specimens were demolding after 24 hours and kept in water with a constant temperature of $22 \pm 2{ }^{\circ} \mathrm{C}$.

The control mixtures K03, K04, K05, K06, $\mathrm{K07}$ and fibrous mixtures were encoded with the indications of L03, L04, L05, LO6, L07.

Table 6. Mixture quantities for $1 \mathrm{~m}^{3}$ concrete. (Self-Elaboration).

\begin{tabular}{|c|c|c|c|c|c|c|c|c|}
\hline \multirow{2}{*}{$\begin{array}{l}\text { Mixture } \\
\text { code }\end{array}$} & \multirow{2}{*}{ Cement (kg) } & \multirow{2}{*}{ Water (kg) } & \multicolumn{3}{|c|}{ Aggregate (kg) } & \multirow{2}{*}{ Fiber (kg) } & \multirow{2}{*}{$\begin{array}{l}\text { Chemical } \\
\text { admixture (kg) }\end{array}$} & \multirow{2}{*}{ Slump (cm) } \\
\hline & & & $0-5(\mathrm{~mm})$ & $\begin{array}{l}5-12 \\
(\mathrm{~mm})\end{array}$ & $\begin{array}{l}12-22 \\
(\mathrm{~mm})\end{array}$ & & & \\
\hline K03 & 650 & 195 & 629 & 465 & 477 & 0 & 3.75 & 17 \\
\hline K04 & 488 & 195 & 686 & 564 & 513 & 0 & 2.25 & 18 \\
\hline K05 & 390 & 195 & 721 & 533 & 539 & 0 & 1.34 & 16 \\
\hline K06 & 325 & 195 & 744 & 550 & 556 & 0 & 0.74 & 15 \\
\hline K07 & 278.6 & 195 & 761 & 562 & 568 & 0 & 0.5 & 17 \\
\hline L03 & 650 & 195 & 618 & 457 & 462 & 78 & 4.5 & 16 \\
\hline L04 & 488 & 195 & 676 & 499 & 505 & 78 & 2.75 & 17 \\
\hline L05 & 390 & 195 & 710.5 & 525 & 531 & 78 & 1.75 & 15 \\
\hline L06 & 325 & 195 & 733.3 & 542 & 548 & 78 & 1 & 16 \\
\hline L07 & 278.6 & 195 & 761 & 562 & 568 & 78 & 0.52 & 15 \\
\hline
\end{tabular}




\section{Fresh state results}

In this study, the slump values and fresh state unit weights of the mixtures were measured as fresh state properties. The results are given in Figures 1 and 2.
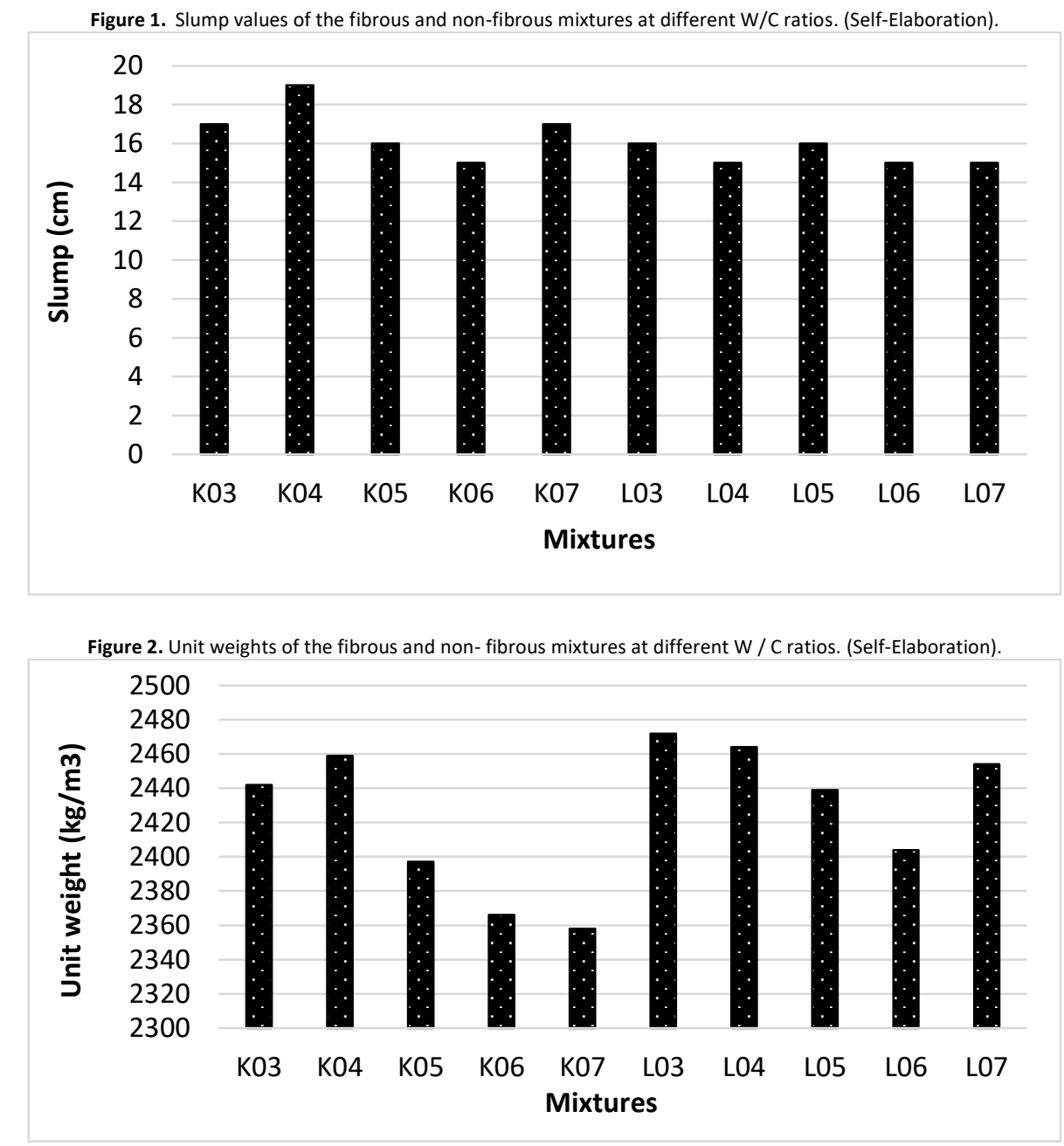

As expected, with the increase of the $\mathrm{W} / \mathrm{C}$ ratio of the mixtures, the admixture demand for providing the desired slump value increased. For example, $0.5 \mathrm{~kg}$ water reducing admixture was used in $\mathrm{K} 07$ mixture to provide $17 \pm 2 \mathrm{~cm}$ whereas $3.75 \mathrm{~kg}$ water reducing admixture was used to increase this value by 7.50 times to provide this value in K03 mixture. The admixture requirement for providing mentioned target slump value in mixtures increased with the use of fiber. The unit weights of the mixtures increased with the decreasing of W/C ratio and the use of steel fiber, which shows that steel fiber in the mixtures was distributed in the mixture homogeneously in the fibrous mixtures.

\section{Hardened state results}

Compressive and splitting tensile test results of concrete mixtures with different sizes and shapes are shown in Figure 3-6 for fibrous and non-fibrous cases. However, strength values could not be measured due to the wall effect of $10 \mathrm{~cm}$ cube and $10 \times 20 \mathrm{~cm}$ cylinder specimens containing $1 \%$ steel fiber with a W / C ratio of 0.7 . 
Figure 3. Compressive strength (MPa) of the non-fibrous mixtures. (Self-Elaboration).

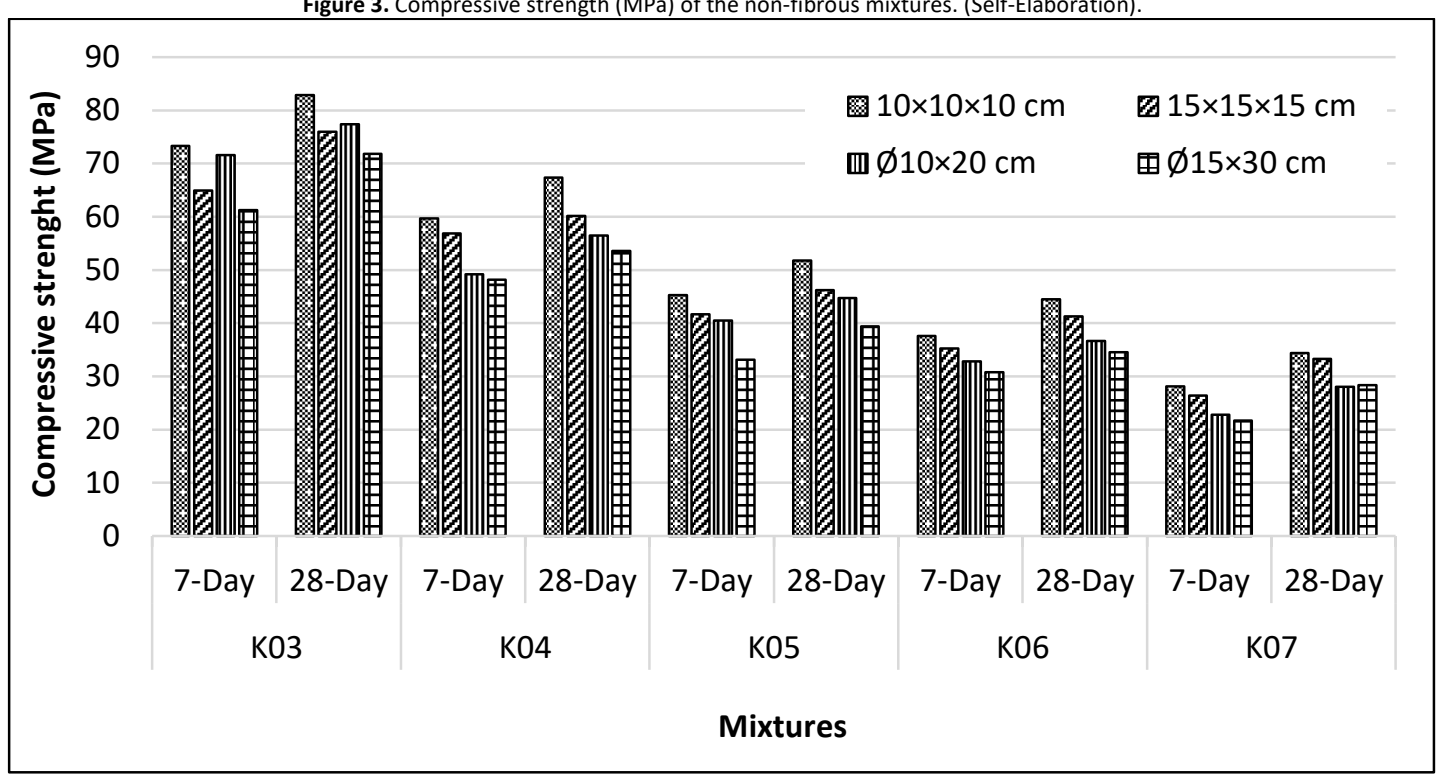

Figure 4. Compressive strength (MPa) of the mixtures containing 1\% steel fiber. (Self-Elaboration).

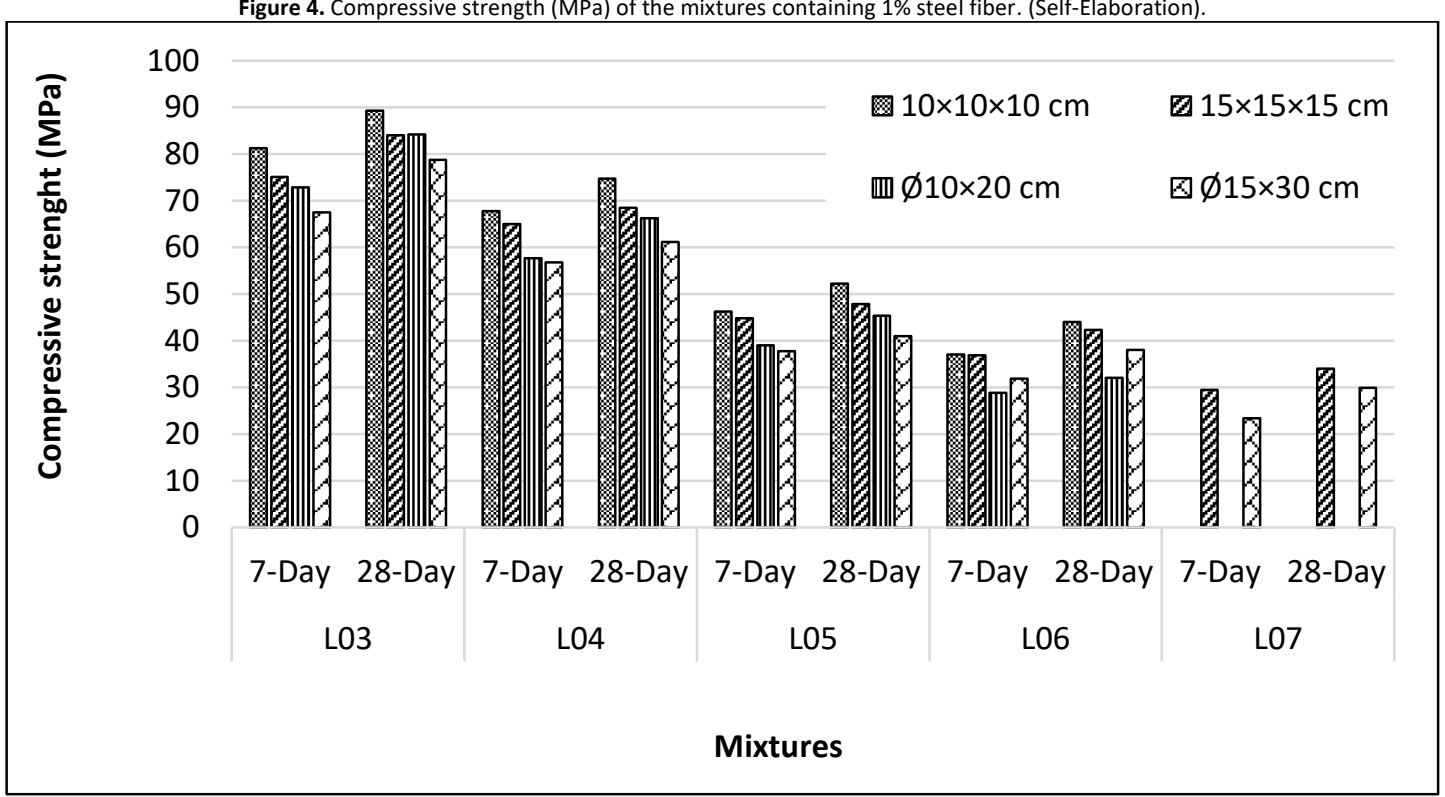



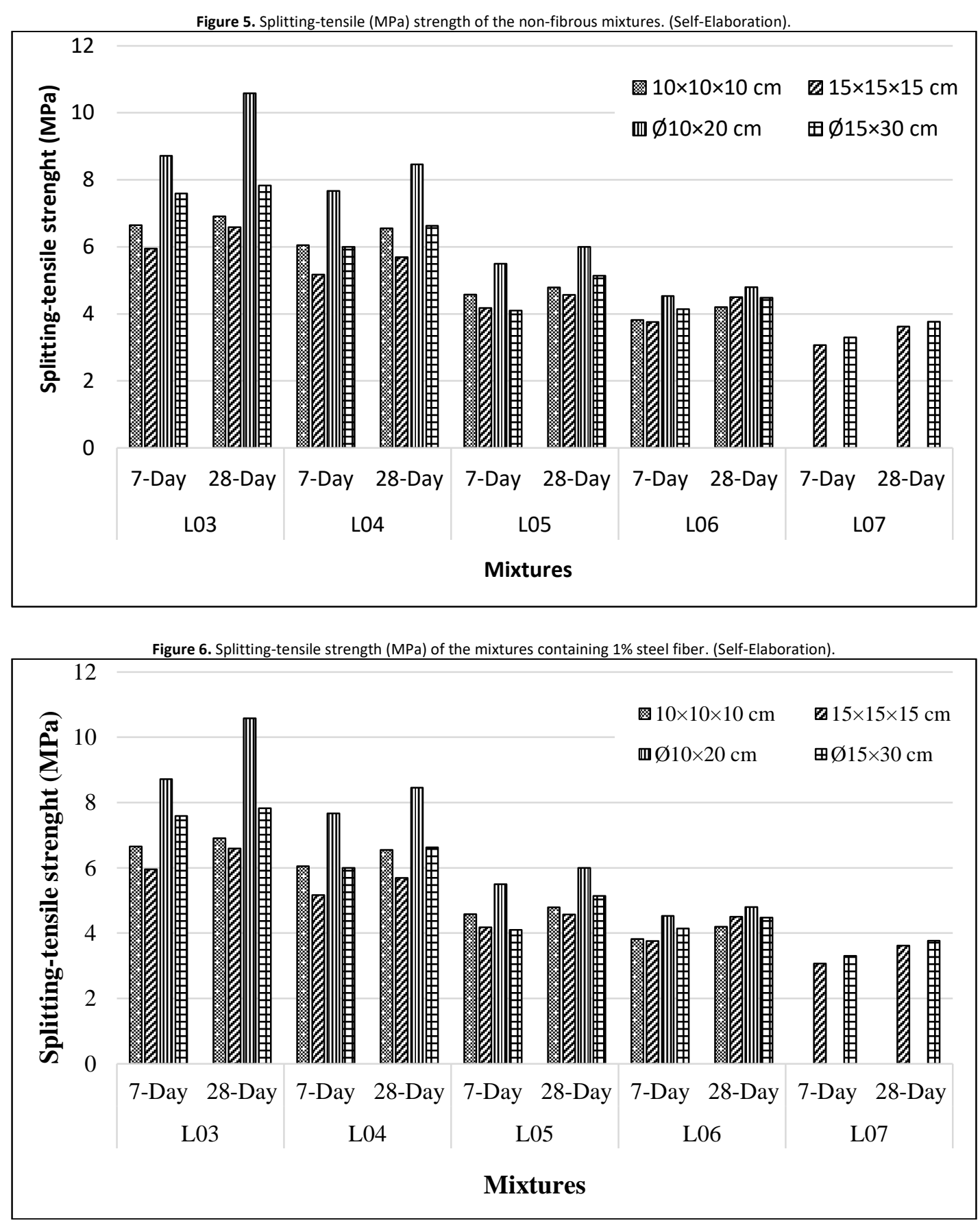

The shape of the specimens with a $0.3 \mathrm{~W} / \mathrm{C}$ ratio subjected to splitting-tensile and compressive tests are shown in Figures 7 and 8, respectively. 
Figure 7. Specimens subjected to the splitting-tensile test. a) Non-fiber specimen; b) Fibrous specimen. (Self-Elaboration).
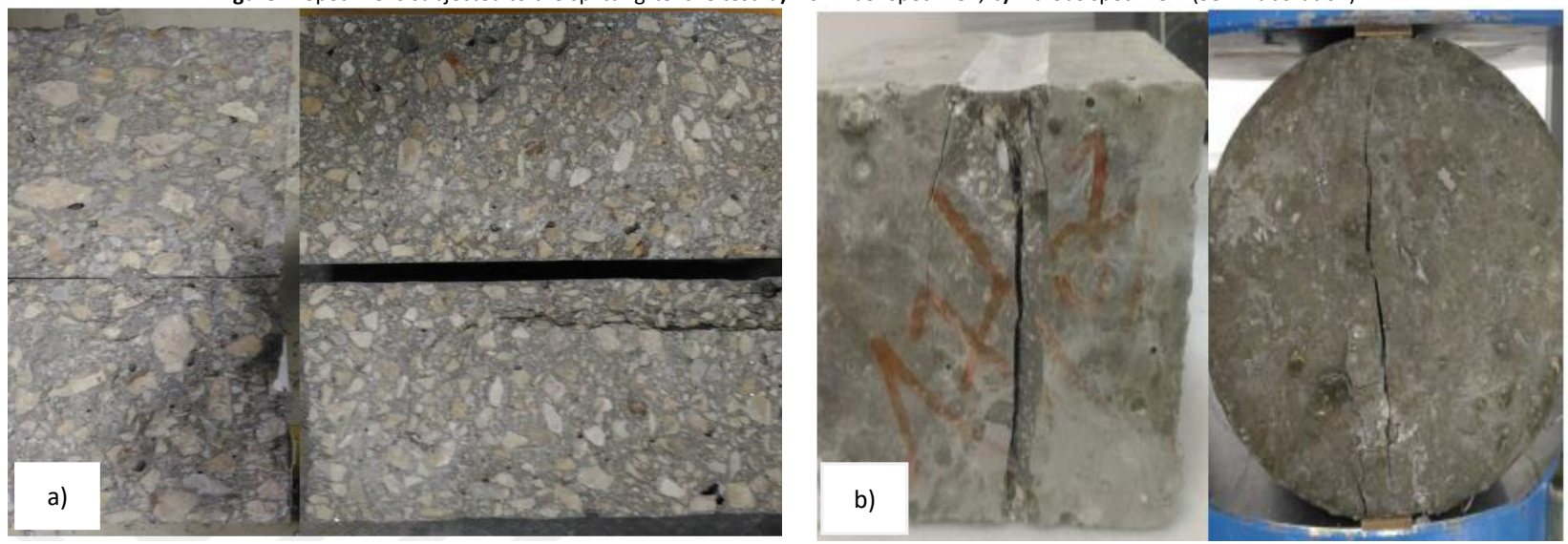

Figure 7. Specimens subjected to the compressive test. a) Non-fiber specimen; b) Fibrous specimen. (Self-Elaboration).
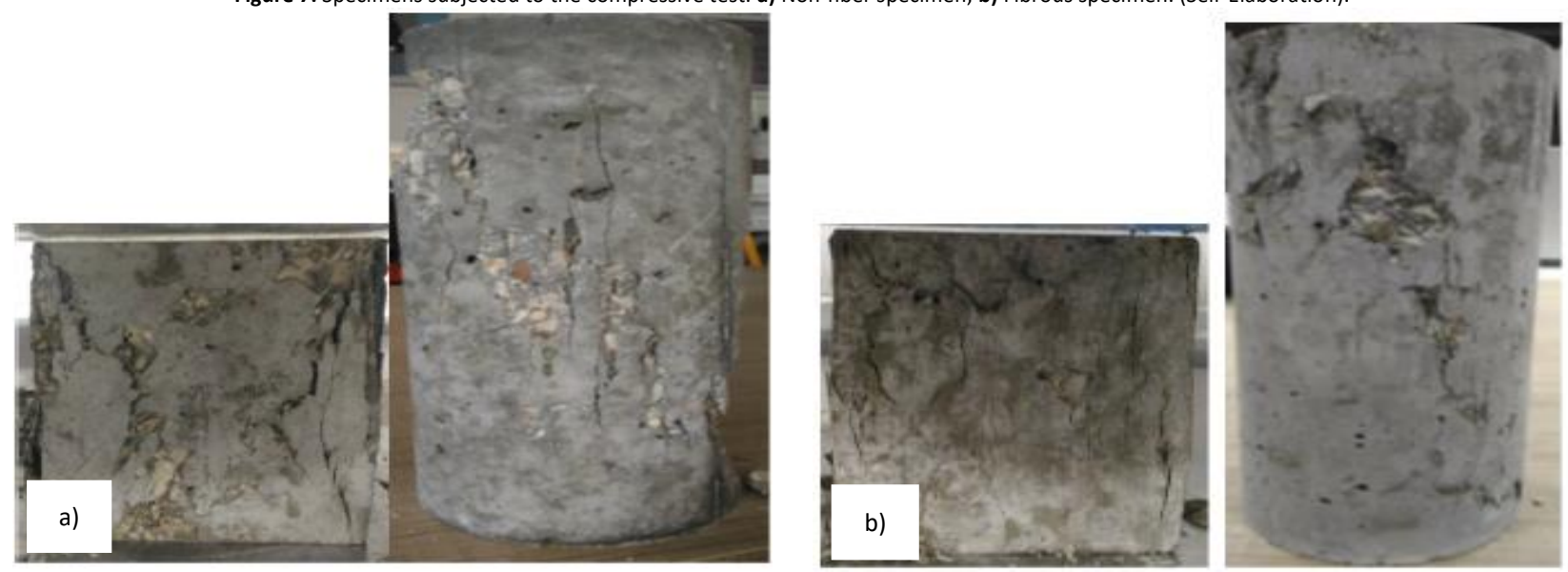

\section{Time-strength relationship}

In order to clearly examine the effect of the time factor on the strength development of specimens with different shapes and sizes, the 7-day relative strength ratio to the 28 day-strength for each mixture is shown in Tables 7 and 8. Regardless of the specimen shape and size, the average 7-day relative strength results for different $\mathrm{W} / \mathrm{C}$ ratios are given in Tables 7 and 8.

Table 7. 7-day compressive strength to 28-day compressive strength ratio for the specimens with different W / C ratio (\%). (Self-Elaboration).

\begin{tabular}{llllll}
\hline Mixture code & $10 \times 10 \times 10 \mathrm{~cm}$ & $15 \times 15 \times 15 \mathrm{~cm}$ & $10 \times 20 \mathrm{~cm}$ & $15 \times 30 \mathrm{~cm}$ & Average (\%) \\
\hline K03 & 88 & 85 & 93 & 85 & 88 \\
K04 & 89 & 95 & 87 & 90 & 90 \\
K05 & 87 & 90 & 91 & 84 & 88 \\
K06 & 85 & 85 & 89 & 89 & 87 \\
K07 & 82 & 79 & 81 & 77 & 80 \\
L03 & 91 & 89 & 87 & 86 & 88 \\
L04 & 91 & 95 & 87 & 93 & 91 \\
L05 & 88 & 94 & 86 & 92 & 90 \\
L06 & 84 & 87 & 90 & 84 & 86 \\
L07 & 0 & 87 & 0 & 78 & 83 \\
\hline
\end{tabular}


Table 8. 7-day splitting-tensile strength to 28 -day splitting-tensile strength for the specimens with different $\mathrm{W} / \mathrm{C}$ ratio (\%). (Self-Elaboration).

\begin{tabular}{llllll}
\hline Mixture code & $10 \times 10 \times 10 \mathrm{~cm}$ & $15 \times 15 \times 15 \mathrm{~cm}$ & $\varnothing 10 \times 20 \mathrm{~cm}$ & $\varnothing 15 \times 30 \mathrm{~cm}$ & Average (\%) \\
\hline K03 & 92 & 86 & 89 & 90 & 89 \\
K04 & 83 & 81 & 93 & 96 & 88 \\
K05 & 95 & 94 & 85 & 83 & 89 \\
K06 & 97 & 94 & 87 & 97 & 94 \\
K07 & 92 & 94 & 86 & 91 & 91 \\
L03 & 96 & 90 & 82 & 97 & 91 \\
L04 & 92 & 91 & 91 & 90 & 91 \\
L05 & 96 & 91 & 92 & 80 & 90 \\
L06 & 91 & 84 & 94 & 92 & 87 \\
L07 & 0 & 85 & 0 & 88 & \\
\hline
\end{tabular}

As known, concrete is a building material which gains strength by time as a result of the hydration. According to the results, the strengths of the concrete mixtures increased by time regardless of the specimen shape, size and fiber usage. As an expected result, strength increase rate observed to be high during the first days of the hydration and decelerates in time (Ashkari, 2015). It can be understood from Table 7 that between $80 \%$ and $90 \%$ of the average compressive strength of the concrete mixtures is provided during the first 7 days. The concrete strength change for low $\mathrm{W} / \mathrm{C}$ ratio and higher strength value was faster during the first 7 days compared to the mixtures with high W/C ratios. For instance, the 7-day compressive strength of the $\mathrm{K03}$ mixture with the $0.3 \mathrm{~W} / \mathrm{C}$ ratio of and without steel fiber was $88 \%$ of the 28 day compressive strength. However, that ratio in $\mathrm{K} 07$ mixture which is prepared with 0.7 water cement ratio and without contain steel fiber is observed as $80 \%$, as can be seen in Table 7 .

This situation is resulted from the high cement content in $\mathrm{K} 03$ mixtures. A certain amount of cement increase results in increase of the hydration rate, thus the concrete strength gain rate advances as well. Concrete mixtures gained nearly $90 \%$ of the 28 -day splitting-tensile strength during the first 7 days (Table 8 ). It was observed that the rate of splitting tensile strength gain of the concrete mixtures with different $\mathrm{W} / \mathrm{C}$ ratio is very close to each other. Similar results were seen in $15 \mathrm{~cm}$ separated cube, $10 \times 20 \mathrm{~cm}$ and $15 \times 30 \mathrm{~cm}$ cylinder specimens as shown in Figure 3-6. Similar behaviors were also observed in fiber-containing mixtures. As a result, it can be seen that the rate of gaining strength for concrete mixtures decreases when $\mathrm{W} / \mathrm{C}$ ratio reduces, which is due to the increased rate of hydration in concretes with low $\mathrm{W} / \mathrm{C}$ ratio (mixtures with high cement content).

\section{Specimen size and shape-strength relationship}

Based upon the strength of $15 \mathrm{~cm}$ cube specimens for each W / C ratio in fibrous and non-fibrous mixtures relative strengths of other specimens were calculated in order to determine the effects of specimen shape and size on compressive strength. The process was applied for both 7-day and 28-day specimens. Obtained results are shown in Figure 9-12.

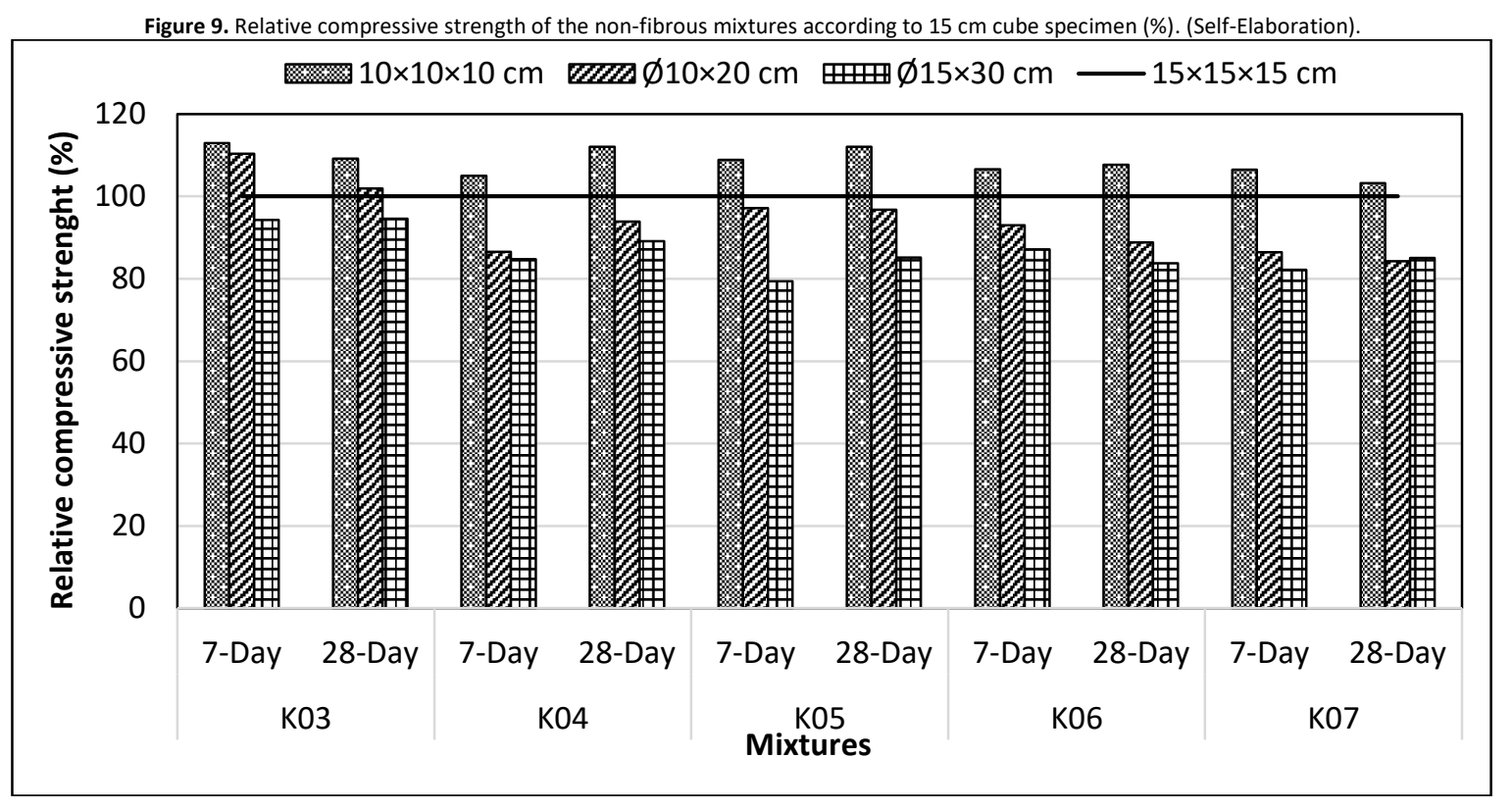


Figure 10. Relative compressive strength of the mixtures with $1 \%$ steel fiber according to $15 \mathrm{~cm}$ cube specimen. (Self-Elaboration).
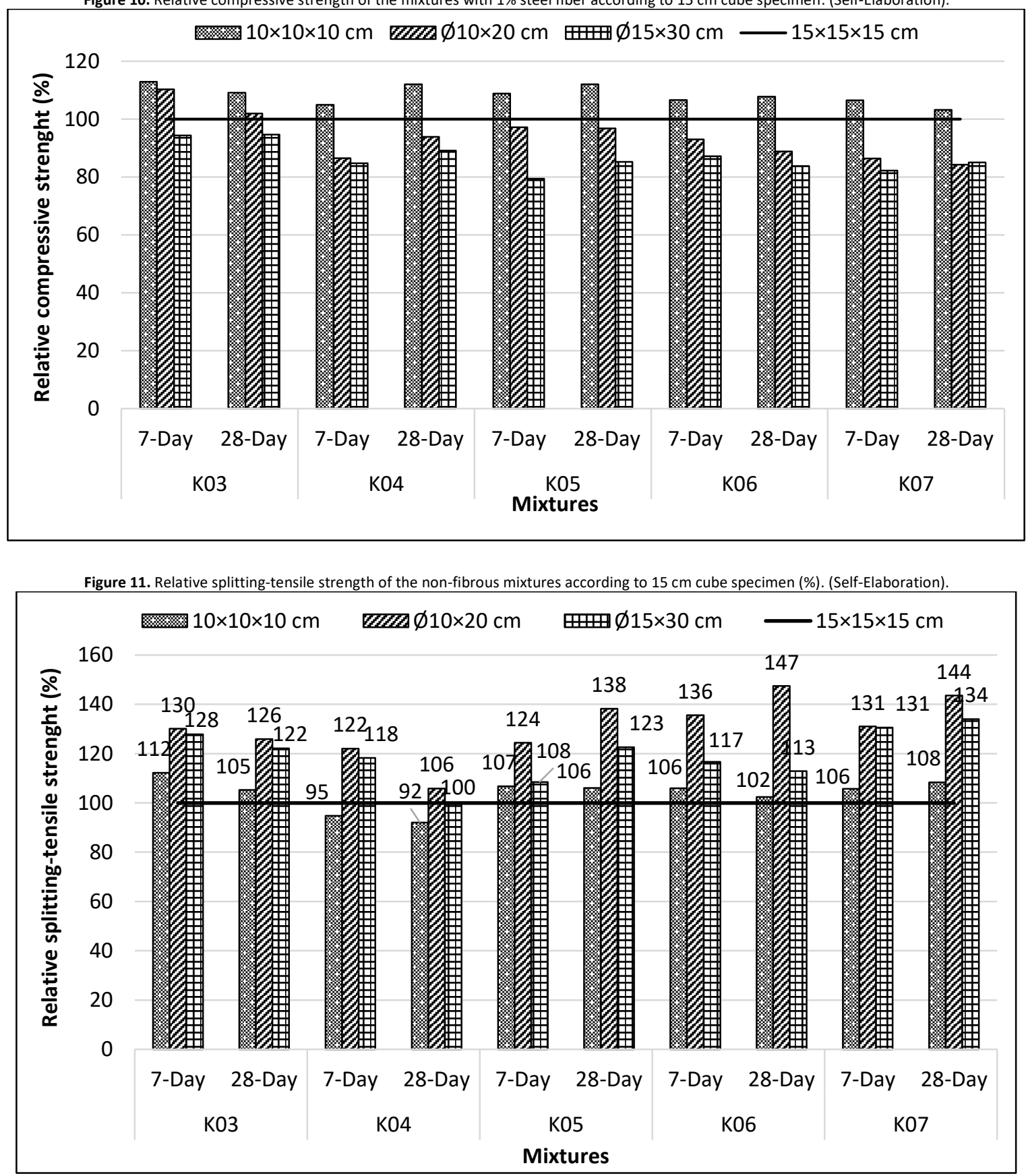
Figure 12. Relative splitting-tensile strengths of the mixtures containing $1 \%$ steel fiber according to $15 \mathrm{~cm}$ cube specimen (\%). (Self-Elaboration)

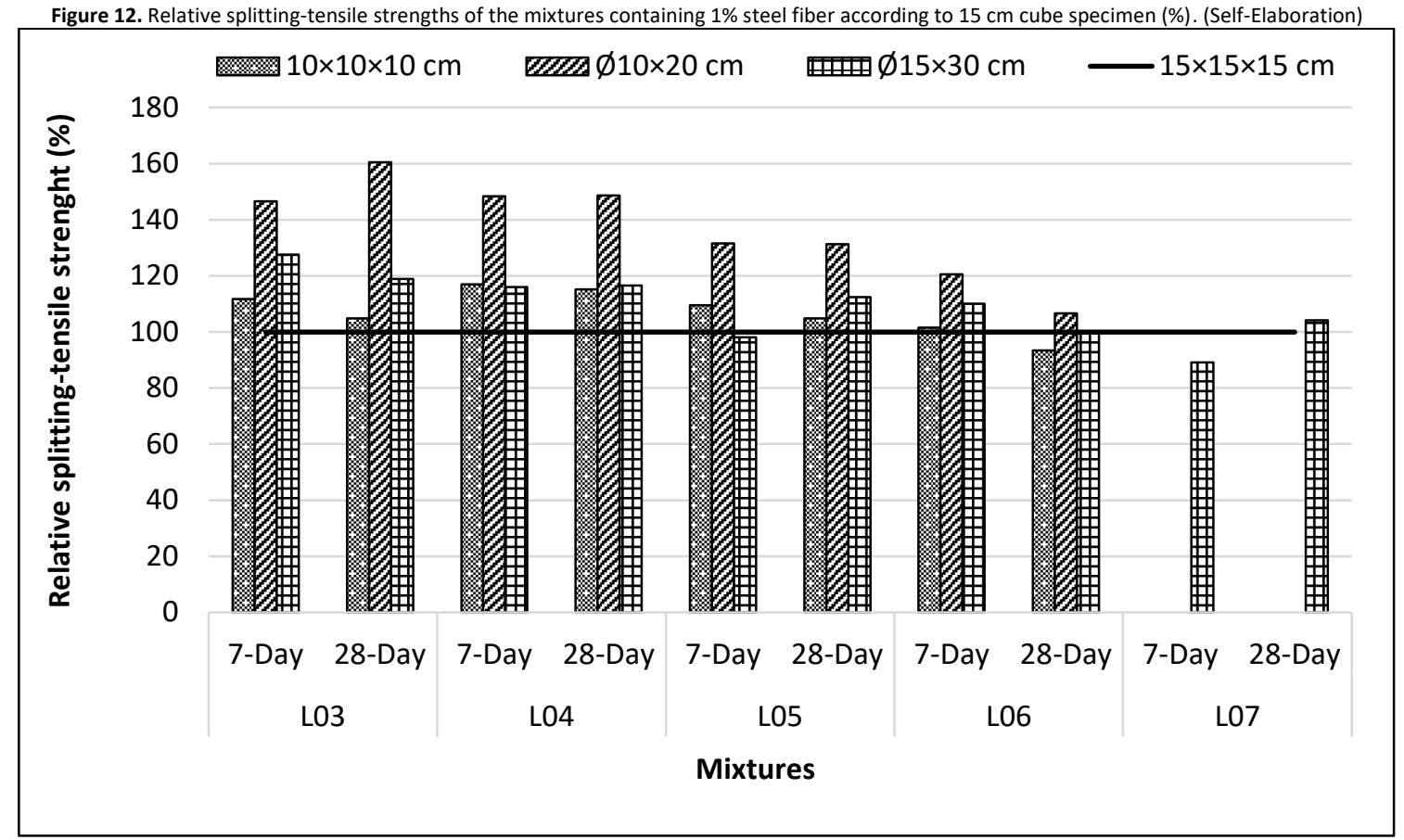

According to the TS EN 206-1 (TS EN 206, 2014) Standard, the ratio of $15 \times 30 \mathrm{~cm}$ cylinder specimen to $15 \mathrm{~cm}$ cube specimen for low, normal and high strength concrete is stated to be between $20 \%$ and $25 \%$. However, as stated by the experimental results performed in this study, regardless of the specimen age and size, the ratio of the cylinder specimen strength to the compressive strength of the cube specimen ranged from $5 \%$ to $20 \%$. Therefore, contrary to the TS EN 206-1(TS EN 206, 2014) Standard, the strength ratio between cylinder and cube mixtures increases as concrete strength increases, which advocates the studies in the literature (Felekoğlu \& Türkel, 2005; Tokyay \& Özdemir, 1997). As can be seen from the results, in non-fibrous mixtures, the strength values were increased as the specimen size decreased regardless of the specimen shape. That situation proves that it supports the size effect rule. Similar results were obtained by Del Viso et al. (2008) and Aslani (2013).

In fiber-containing mixtures, the compressive strength of small-sized specimens $(10 \mathrm{~cm}$ cube and $10 \times 20 \mathrm{~cm}$ cylinder) at a low W/C ratio was greater than that of the standard specimens ( $15 \mathrm{~cm}$ cube and $15 \times 30 \mathrm{~cm}$ cylinder). However, a reverse situation was observed in high $\mathrm{W} / \mathrm{C}$ ratios (Figure 4). In all series, the highest splitting tensile strength was observed in $10 \times 20 \mathrm{~cm}$ cylinder specimens and the lowest splitting tensile strength was observed in cube specimens with $15 \mathrm{~cm}$ separation (Figure 5 and Figure 6). As seen in Figure 9, the compressive strength ratio of $10 \mathrm{~cm}$ cube specimens to $15 \mathrm{~cm}$ cube specimens in 7 -day was $106 \%$ to $113 \%$ and in 28 -day $103 \%$ to $109 \%$. At lower W/C ratios, this phenomenon became even more obvious. The ratio of $10 \times 20 \mathrm{~cm}$ cylinder specimens to $15 \mathrm{~cm}$ cube specimens was $110 \%$ and $102 \%$ in $\mathrm{K} 03$ mixture for 7 and 28 -day specimens, respectively. In other non-fibrous mixtures, this ratio was observed to range from $85 \%$ to $97 \%$. With the increase of concrete strength, the compressive strength of $10 \times 20 \mathrm{~cm}$ cylinder concrete specimens increased slightly compared to the $15 \mathrm{~cm}$ cube specimens.

However, the compressive strength of $10 \times 20 \mathrm{~cm}$ cylinder specimens was lower than the $15 \mathrm{~cm}$ cube specimens in normal and low strength concrete. It is seen that the ratio of compressive strength of standard cylinder specimen with dimensions of $15 \times 30 \mathrm{~cm}$ to the strength of standard cube specimens of $15 \mathrm{~cm}$ is between $82 \%$ and $95 \%$. These ratios increased with the increase of concrete strength. Similar results were obtained by other researchers (Ashkari, 2015; Çopuroğlu, 2001). As it seen in Figure 8, the compressive strength ratio of $10 \mathrm{~cm}$ cube specimens in fibrous mixtures compared to $15 \mathrm{~cm}$ cube specimens was between $100 \%$ and $108 \%$ for 7 -day specimens and $104 \%$ to $109 \%$ for 28 -day specimens. As a result, the compressive strength of fibrous cube specimen was less affected by the specimen size than non-fibrous cube specimens. As emphasized earlier, excessive wall effect was observed in $10 \mathrm{~cm}$ cube and $10 \times 20 \mathrm{~cm}$ cylinder specimens in L07 mixture with a W/C ratio of 0.7 containing $1 \%$ fiber. This situation is clearly understood from Figure 11. Therefore, the strength values of these specimens could not be measured. It is thought to be due to the lack of sufficient binder and fine material in the L07 mixture.

In these mixtures, $60 \%$ of the total aggregate is used with coarse aggregate including the largest grain diameter of 22 $\mathrm{mm}$ and steel fiber as $1 \%$ of its total volume. For this reason, especially in the case of small specimen sizes, it became impossible to properly compress the mixture and to distribute the fiber beads uniformly. Due to the insufficient binding 
material between the aggregate grains and the inner surface of the mold, the surrounding of the coarse aggregate could not be covered by the matrix. Therefore, the wall effect shown in Figure 13 occurred.

It was determined in the previous studies that the fine aggregate content should be increased by $10 \%$ in order to place the $10 \mathrm{~cm}$ cube concrete specimen made from the aggregate with the largest grain diameter of $19 \mathrm{~mm}$ according to the larger specimens in the mold by full compression (Neville A.M, 1995). Results prove that the use of small sized specimens in fibrous concrete was not appropriate. The strength ratio of the $10 \times 20 \mathrm{~cm}$ cylinder specimens to $15 \mathrm{~cm}$ cube specimens in fibrous mixtures was between $78 \%-97 \%$ and $76 \%-100 \%$ for 7 and 28 -day specimens, respectively. With the increase in concrete strength class, the strength of $10 \times 20 \mathrm{~cm}$ cylinder specimens increased compared to $15 \mathrm{~cm}$ cube specimens. The compressive strength of $15 \times 30 \mathrm{~cm}$ standard cylinder samples in fibrous mixtures is seen to be between $80 \%$ and $94 \%$ of the $15 \mathrm{~cm}$ standard cube samples. These ratios increased with the increase of the concrete strength. It was found out that these ratios are very close to each other in fibrous and non-fibrous mixtures with increasing compressive strength.

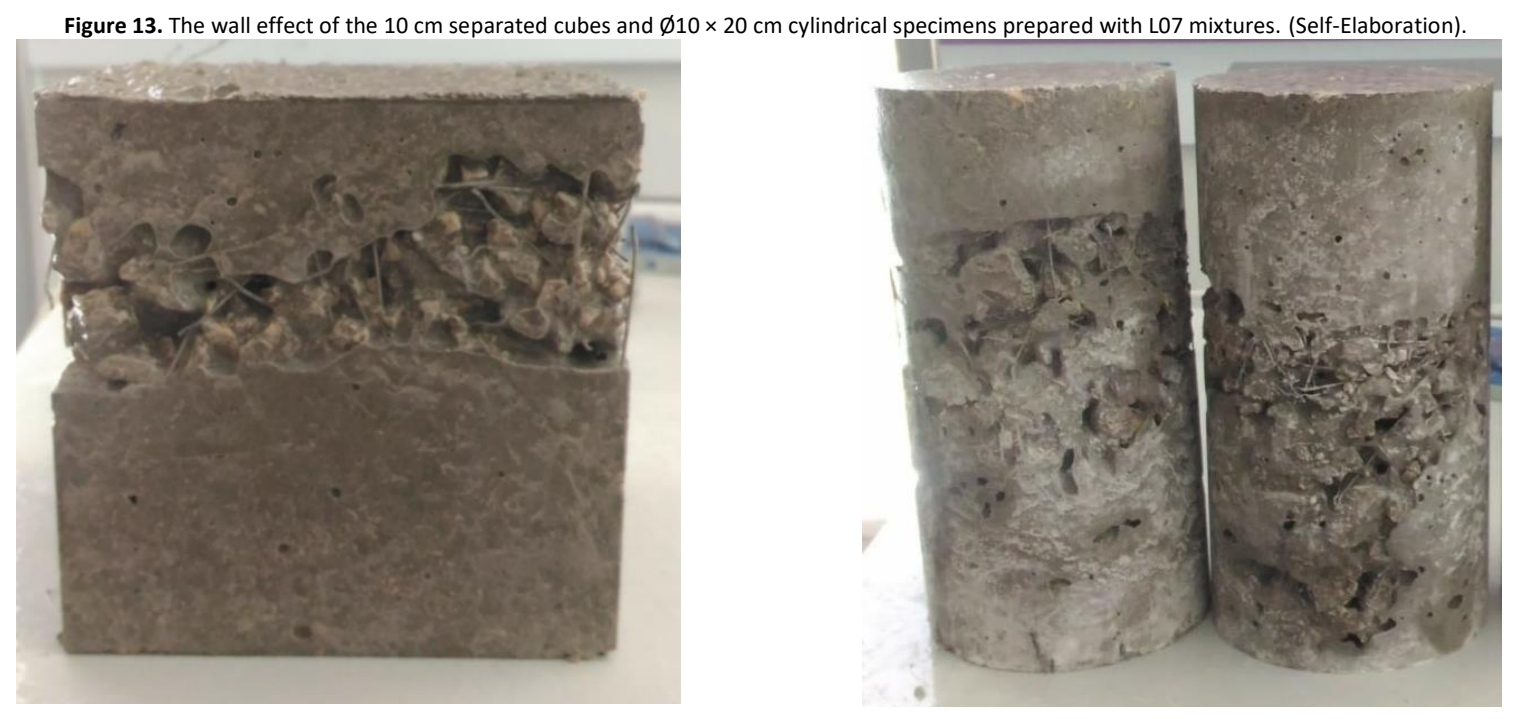

As it shown in Figure 11, the splitting tensile strength ratio of $10 \mathrm{~cm}$ cube specimen to $15 \mathrm{~cm}$ cube specimen in nonfibrous mixtures is between $102 \%$ and $112 \%$ except the K04 mixture. In the study conducted by Tuğal and Arıcı (2011), it was determined that the splitting-tensile strength increased with the reduction of the specimen size. The splitting tensile strength ratio of $10 \times 20 \mathrm{~cm}$ concrete specimens to $15 \mathrm{~cm}$ concrete specimens was found to be between $106 \%$ and $147 \%$. This ratio was found to be higher in low strength concrete. The splitting-tensile strength ratio of $15 \times 30 \mathrm{~cm}$ cylinder specimens to $15 \mathrm{~cm}$ cube specimens was observed between $100 \%$ and $134 \%$. As shown in Figure 12 , the fibertensile strength of $10 \mathrm{~cm}$ cube specimens in fibrous mixtures was found to be between $93 \%$ and $115 \%$ of $15 \mathrm{~cm}$ cube specimens. Splitting-tensile strength of $10 \mathrm{~cm}$ cube specimens with low W/C was higher than that of $15 \mathrm{~cm}$ cube specimen. However, that ratio reduces with high $\mathrm{W} / \mathrm{C}$ ratio and low binding material.

This situation is thought to be due to the wall effect (Çopuroğlu, 2001). The splitting-tensile strength of $10 \times 20 \mathrm{~cm}$ cylinder specimens was found to be between $107 \%$ and $161 \%$ of $15 \mathrm{~cm}$ specimens. The splitting-tensile strength of $15 \times 30 \mathrm{~cm}$ cylinder specimens was found to be between $89 \%$ and $128 \%$ of $15 \mathrm{~cm}$ specimens.

\section{Relationship between the compressive and splitting-tensile strengths}

The ratio of the compressive strength to the splitting tensile strength of the specimens is summarized in Table 9 including fibrous and non-fibrous mixtures for all W/C ratios. In addition, the splitting-tensile strength results independent from the $\mathrm{W} / \mathrm{C}$ ratio in the mixture is given in Table 9. 
Table 9. Compressive strength ratio of the 7 and 28-day splitting-tensile strength of different cube and cylinder specimens. (Self-Elaboration).

\begin{tabular}{|c|c|c|c|c|c|c|c|c|}
\hline \multirow[t]{2}{*}{ Mixture code } & \multicolumn{2}{|c|}{$\sigma_{\mathrm{b} 15} / \sigma_{\mathrm{t} 15}$} & \multicolumn{2}{|c|}{$\sigma_{\mathrm{b} 15 \times 30 / \sigma_{\mathrm{t} 15 \times 30}}$} & \multicolumn{2}{|c|}{$\sigma_{\mathrm{b} 10 /} \sigma_{\mathrm{t} 10}$} & \multicolumn{2}{|c|}{$\sigma_{\mathrm{b} 10 \times 20 / \sigma_{\mathrm{t} 10 \times 20}}$} \\
\hline & 7-Day & 28-Day & 7-Day & 28-Day & 7-Day & 28-Day & 7-Day & 28-Day \\
\hline K03 & 16.44 & 16.51 & 12.13 & 12.79 & 16.55 & 18.71 & 13.94 & 13.37 \\
\hline K04 & 16.43 & 14.05 & 11.78 & 12.58 & 18.19 & 20.53 & 11.66 & 12.46 \\
\hline K05 & 14.13 & 14.72 & 10.34 & 10.23 & 14.38 & 16.44 & 11.04 & 10.31 \\
\hline K06 & 13.06 & 14.39 & 9.76 & 10.67 & 13.14 & 15.55 & 8.96 & 8.67 \\
\hline K07 & 11.68 & 13.81 & 7.35 & 8.76 & 11.76 & 14.38 & 7.71 & 8.11 \\
\hline Average & 14.35 & 14.70 & 10.27 & 11.01 & 14.80 & 17.12 & 10.66 & 10.58 \\
\hline L03 & 12.62 & 12.75 & 8.89 & 10.06 & 12.22 & 12.93 & 8.36 & 7.96 \\
\hline L04 & 12.57 & 12.04 & 9.49 & 8.08 & 11.2 & 11.41 & 7.52 & 6.67 \\
\hline L05 & 10.72 & 10.47 & 9.21 & 7.96 & 10.09 & 10.9 & 7.09 & 7.56 \\
\hline L06 & 9.81 & 9.4 & 7.7 & 8.48 & 9.69 & 10.48 & 6.36 & 6.67 \\
\hline L07 & 9.6 & 9.39 & 7.09 & 7.93 & - & - & - & - \\
\hline Average & 11.06 & 10.81 & 8.48 & 8.50 & 10.8 & 11.43 & 7.33 & 7.22 \\
\hline
\end{tabular}

According to the results in Table 9, the ratio of compression strength/splitting-tensile strength increased with the increasing of compressive strength of concrete mixture independently from the fiber usage and specimens shape. Similar results were obtained from the study conducted by Çopuroğlu (2001). The ratio of compressive strength to splitting tensile strength was found to be 14.5 for $15 \mathrm{~cm}$ cube specimens in non-fibrous mixtures, and 10.6 for $15 \times 30$ $\mathrm{cm}$ cylinder specimens. The ratios for $10 \mathrm{~cm}$ cubes and $10 \times 20 \mathrm{~cm}$ cylinders are 15.96 and 10.62, respectively. As a result, the ratio of compressive strength to the splitting tensile strength was higher in cube specimens than in cylindrical specimens regardless of the fiber use. In addition, it is understood from Table 9 that regardless of the concrete strength class, in non-fibrous mixtures, the ratio of compressive strength / splitting-tensile strength is higher than the fibrous mixture.

The ratio of compressive strength to the splitting tensile strength in fibrous mixtures was found to be 10.94 in $15 \mathrm{~cm}$ cube specimens and 8.49 in $15 \times 30 \mathrm{~cm}$ cylinder specimens, respectively. Likewise, for $10 \mathrm{~cm}$ cube and $10 \times 20 \mathrm{~cm}$ cylinder specimens, this ratio was found to be 11.12 and 7.27, respectively. According to the results obtained, the findings related to the splitting-tensile and compressive strengths are as follows:

a) Regardless of the use of the steel fiber and the shape of the specimen, the ratio of compressive strength / splitting-tensile strength increased with the increasing of concrete strength class.

b) In non-fibrous mixtures, the ratio of the compressive strength of $15 \mathrm{~cm}$ cube specimen to the splitting tensile strength was $35 \%$ higher than that of $15 \times 30 \mathrm{~cm}$ cylinder specimens. It has been seen that the ratio of compressive strength/splitting-tensile strength was approximately $50 \%$ higher in $10 \mathrm{~cm}$ cube specimens than $10 \times 20 \mathrm{~cm}$ cylinder specimens.

c) In fiber-containing blends, the ratio of compressive strength / splitting-tensile strength of $15 \mathrm{~cm}$ cube specimens was $29 \%$ higher than $15 \times 30 \mathrm{~cm}$ cylinder specimens. This ratio was found to be $53 \%$ higher in $10 \mathrm{~cm}$ cube specimens than $10 \times 20 \mathrm{~cm}$ cylinder specimens.

d) It was understood from the test results that the ratio of compressive strength / splitting-tensile strength of 15 $\mathrm{cm}$ cube specimens was $32 \%$ higher in non-fibrous mixtures than fibrous mixtures. This ratio was determined as $43 \%, 26 \%$ and $46 \%$ for $10 \mathrm{~cm}$ cube, $15 \times 30 \mathrm{~cm}$ cylinder and $10 \times 20 \mathrm{~cm}$ cylinder specimens, respectively.

Regardless of the specimen size, the relationship between the splitting-tensile compressive strength of the cylinder and the cube specimens is demonstrated in Figures 14 and 15 for non-fibrous and fibrous conditions, respectively. 
Figure 14. Relationship between the splitting tensile and compressive strength of the cube and cylinder specimen of non-fibrous mixtures. (Self-Elaboration).

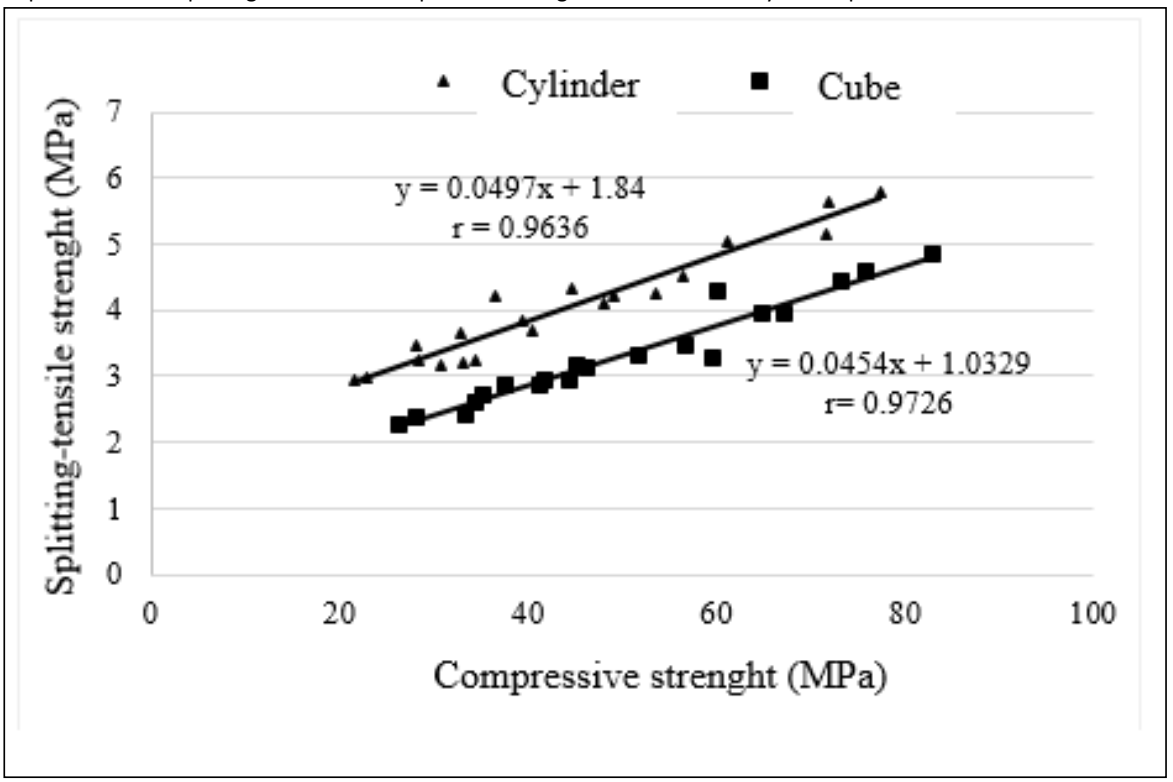

Figure 15. Relationship between the splitting tensile and compressive strength of the cube and cylinder specimens of fibrous mixtures. (Self-Elaboration).

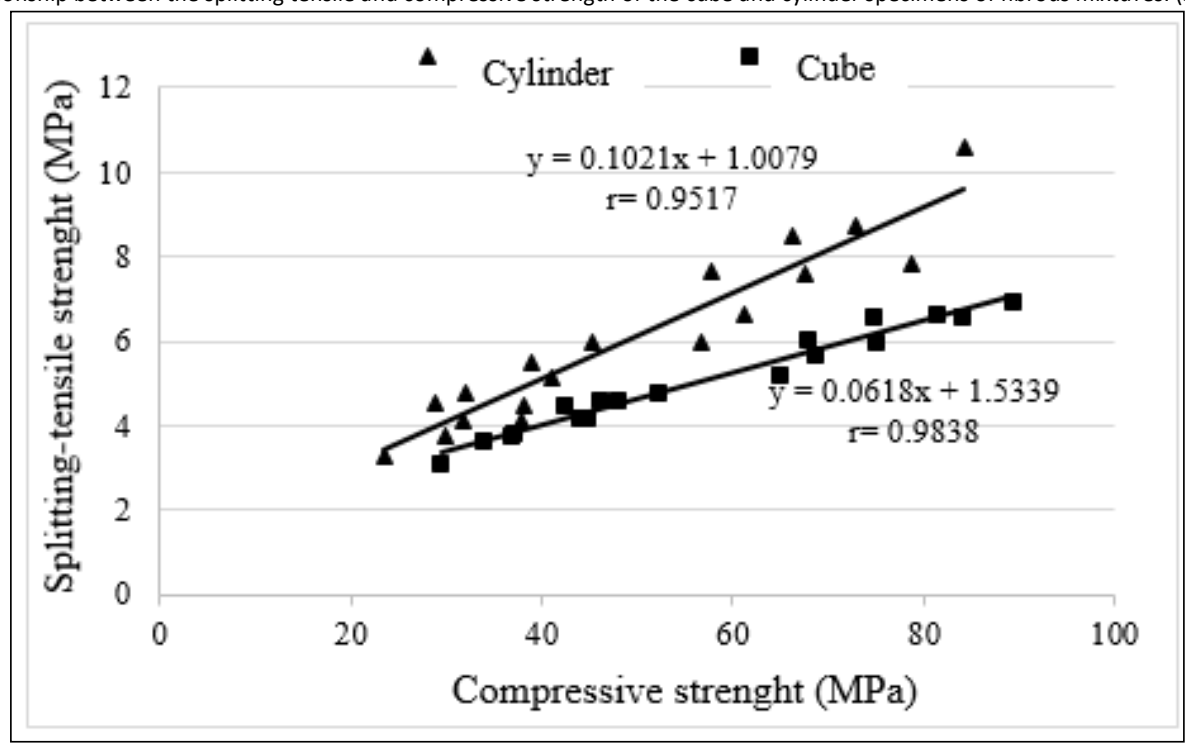

It is also understood from Figures 14 and 15 that there is a strong linear relationship between compressive and splittingtensile strengths regardless of the fiber use and specimen shape. This behavior in cube specimens was more distinct than the cylinder specimens.

\section{The effect of the use of steel fiber on the strength of concrete specimens}

The strength of the mixtures with $1 \%$ steel fiber and non-fibrous mixtures with the same $\mathrm{W} / \mathrm{C}$ ratio is given in Table 10 and 11 , respectively.

\begin{tabular}{ccccccc}
\multicolumn{7}{c}{ Table 10. Compressive strength ratio of the fibrous mixtures compared to non-fibrous mixtures (\%). (Self-Elaboration). } \\
\hline Specimens (cm) & Curing time (Day) & L03/K03 & L04/K04 & L05/K05 & L06/K06 & L07/K07 \\
\hline $10 \times 10 \times 10$ & 7 & 111 & 114 & 102 & 98 & 0 \\
& 28 & 108 & 111 & 101 & 99 & 0 \\
$15 \times 15 \times 15$ & 7 & 116 & 114 & 107 & 105 & 112 \\
& 28 & 111 & 114 & 104 & 102 & 102 \\
$10 \times 20$ & 7 & 102 & 117 & 96 & 88 & 0 \\
& 28 & 109 & 117 & 100 & 87 & 0 \\
$15 \times 30$ & 7 & 110 & 118 & 114 & 104 & 108 \\
& 28 & 110 & 114 & 104 & 110 & 106 \\
\hline
\end{tabular}


Table 11. Splitting-tensile strength ratio of the fibrous mixtures compared to non-fibrous mixtures (\%). (Self-Elaboration).

\begin{tabular}{ccccccc}
\multicolumn{7}{c}{ Table 11. Splitting-tensile strength ratio of the fibrous mixtures compared to non-fibrous mixtures (\%). (Self-Elaboration). } \\
\hline Specimens $(\mathrm{cm})$ & Curing tim (Day) & L03/K03 & L04/K04 & L05/K05 & L06/K06 & L07/K07 \\
\hline $10 \times 10 \times 10$ & 7 & 150 & 184 & 145 & 134 & 0 \\
& 28 & 143 & 166 & 144 & 143 & 0 \\
$15 \times 15 \times 15$ & 7 & 151 & 149 & 142 & 139 & 136 \\
& 28 & 143 & 133 & 146 & 157 & 150 \\
$10 \times 20$ & 7 & 170 & 182 & 150 & 124 & 0 \\
& 28 & 183 & 187 & 138 & 113 & 0 \\
$15 \times 30$ & 7 & 150 & 147 & 128 & 131 & 112 \\
& 28 & 139 & 156 & 134 & 138 & 117 \\
\hline
\end{tabular}

As shown in Table 10 and 11, $15 \mathrm{~cm}$ cube specimens, the compressive strength of fibrous mixture was $102 \%$ and $117 \%$ of compressive strength of non-fibrous mixtures and this ratio in splitting-tensile strength was 133-157\%. Similarly, an increase of $99 \%$ to $114 \%$ in compressive strength of fibrous mixtures was observed. This ratio for splitting-tensile strength was $143 \%$ to $166 \%$ of non-fibrous mixtures. In the $15 \times 30 \mathrm{~cm}$ cylinder specimens, an increase of $104 \%$ to $114 \%$ was observed in the compressive strength values of fibrous mixtures compared to non-fibrous mixtures, while an increase of 134 to $156 \%$ in spitting-tensile strength was recorded. According to the results, no significant effect of the use of steel fiber on the compressive strength of low and normal strength concrete was observed. In specimens with small size (10 cm cube, $10 \times 20 \mathrm{~cm}$ cylinder) and with high W / C ratio, decrease in the compressive strength of fibrous concrete mixtures was observed.

The compressive strength of the mixture with $\mathrm{W} / \mathrm{C}$ ratio of 0.7 could not be measured due to the excessive wall effect on the specimens. This is thought to be due to the fact that the binder material and fine aggregate are small and that the fibers do not homogeneously disperse in the mixture and thus lead to agglomeration. Therefore, the use of smallsized specimens in low-strength fibrous concretes was not suitable. Similar behaviors were observed in the splitting tensile strength of the concrete mixtures. With the use of fiber, the spitting-tensile strength of the concrete mixtures was increased between 1.12 and 1.87. However, as observed in the measurement of the compressive strength of concrete mixtures, the splitting-tensile strength of small-sized specimens prepared at a W / C ratio of 0.7 could not be measured. However, with the use of fiber in high-strength concrete, a $10 \%$ increase in compressive strength of the concrete mixtures was determined.

Conclusions

The results summarized below were obtained based on the materials used and in accordance with the methods applied.

- As expected, the strength of concrete mixtures increased over time, regardless of the specimen shape, size and fiber utilization.

- In the concrete with low W/C ratio, the first 7-day strength development was faster than the mixtures with high water / cement ratios.

- $85 \%$ of the 28 -day compressive strength was gained in the first 7 days.

- As expected, the strength of the concrete mixtures increased with the reduction of $\mathrm{W} / \mathrm{C}$ ratio, regardless of fiber use, specimen size and shape.

- It has been observed that with the increase in concrete strength class, the strength ratio between cylinder and cube specimen has increased.

- In non-fibrous mixtures, strength values were increased as the specimen size decreased, regardless of the specimen shape.

- In the fiber-containing mixtures, compared to the standard specimens ( $15 \mathrm{~cm}$ cubes and $15 \times 30 \mathrm{~cm}$ cylinders), the small specimens (10 cm cubes and $10 \times 20 \mathrm{~cm}$ cylinders) showed better performance in terms of compressive strength. However, in the case of high w/c ratio, the compressive strength decreased compared to the standard specimens owing to the existence of wall effect in small size specimens. In this context, the strength values of the small-sized fibrous specimens with a W/C ratio of 0.7 could not be measured because of the excessive wall effect in the specimen. Therefore, small size specimens do not exhibit real behavior in terms of strength in fiber-containing mixtures with high $\mathrm{W} / \mathrm{C}$ ratio.

- It was found that the compressive strength of fiber-containing cube specimen was less affected by specimen size than non-fibrous cube specimens.

- Regardless of fiber usage and specimen shape, an increase was observed in the compressive strength/splitting tensile strength ratio with the compressive strength increase of the concrete mixture. 
- Regardless of the steel fiber use, the ratio of compressive strength to splitting-tensile strength in cubic specimens was higher than that of cylindrical specimens. Furthermore, it was found that, in fiber-free mixtures, compressive strength/ splitting-tensile strength ratio was higher than the fiber containing mixtures, regardless of the concrete strength class.

- Regardless of the steel fiber usage and specimens shape, a strong linear relationship was found between compressive and splitting-tensile strengths. This behavior in cube specimens was more distinct than the cylindrical specimens.

- It was observed that the use of steel fiber has no significant effect on the compressive strength of the concrete with low and normal strength class. However, with the use of fiber in high strength concrete, a $10 \%$ increase in compressive strength of concrete mixtures was determined. 
Aitcin, P. C., Miao, B., Cook, W. D., \& Mitchell, D. (1994). Effects of size and curing on cylinder compressive strength of normal and high-strength concretes. ACI Materials Journal, 91(4), 349-354. https://doi.org/10.14359/4044

Alex, X. I., \& Arunachalam, K. (2019). Flexural behavior of fiber reinforced lightweight concrete. Revista de La Construccion, $18(3)$, 536-544. https://doi.org/10.7764/RDLC.18.3.536

Ashkari, H. (2015). Effect of geometry of concrete specimen on compressive strength [Master Thesies, Ege University, Graduate School of Natural and Applied Sciences, P 115]. https://tez.yok.gov.tr/ Aslani, F. (2013). Effects of specimen size and shape on compressive and tensile strengths of selfcompacting concrete with or without fibres. Magazine of Concrete Research, 65(15), 914-929. https://doi.org/10.1680/macr.13.00016

CEB-FIP MC10. (2010). Model Code 2010. In fib Model Code for Concrete Structures 2010. https://www.fib-international.org/

Che, Y., Ban, S. L., Cui, J. Y., Chen, G., \& Song, Y. P. (2011). Effect of specimen shape and size on compressive strength of concrete. In Advanced Materials Research (Vol. 163, pp. 1375-1379). Trans Tech Publications Ltd.

Çopuroğlu, O. (2001). Specimen size and shape effect on compressive and tensile strength of concrete [Ege University]. https://tez.yok.gov.tr/

Dehestani, M., Nikbin, I. M., \& Asadollahi, S. (2014). Effects of specimen shape and size on the compressive strength of self-consolidating concrete (SCC). Construction and Building Materials, 66, 685-691. https://doi.org/10.1016/j.conbuildmat.2014.06.008

Del Viso, J. R., Carmona, J. R., \& Ruiz, G. (2008). Shape and size effects on the compressive strength of high-strength concrete. Cement and Concrete Research, 38(3), 386-395. https://doi.org/10.1016/j.cemconres.2007.09.020

Felekoğlu, B., \& Türkel, S. (2005). Effects of specimen type and dimensions on compressive strength of concrete. Journal of Science, 18(4), 639-645.

Gyurkó, Z., \& Nemes, R. (2020). Specimen size and shape effect on the compressive strength of normal strength concrete. Periodica Polytechnica Civil Engineering, 64(1), 276-286. https://doi.org/10.3311/PPci.15338

Khalilpour, S., \& Dehestani, M. (2021). Enhanced specimen size and shape effect models for high-strength fibre-reinforced concrete. Proceedings of the Institution of Civil Engineers - Structures and Buildings, ISSN 0965-0911, 1-16. https://doi.org/10.1680/jstbu.19.00086

Köroglu, M. A., \& Ashour, A. (2019). Mechanical properties of self-compacting concrete with recycled bead wires. Revista de La Construcción, 18(3), 501-512. https://doi.org/10.7764/RDLC.18.3.501

Li, M., Hao, H., Shi, Y., \& Hao, Y. (2018). Specimen shape and size effects on the concrete compressive strength under static and dynamic tests. Construction and Building Materials, 161, 84-93. https://doi.org/10.1016/j.conbuildmat.2017.11.069

Mardani-Aghabaglou, A., Illhan, M., \& Özen, S. (2019). The effect of shrinkage reducing admixture and polypropylene fibers on drying shrinkage behaviour of concrete. Cement, Wapno, Beton, 24(3), 227-238. https://doi.org/10.32047/CWB.2019.24.3.227

Neville A.M. (1995). Properties of Concrete. In Brithish library cataloguing in publication data (Fourth edi). Pearson education limited.

Ouedraogo, H. A., Özen, S., Kobya, V., Sagiroglu, S., \& Mardani-Aghabaglou, A. (2021). Comparıson of fresh and hardened propertıes of self-compactıng concrete mixture from different aspect ratıo of steel fiber view point. Journal of Green Building, 16(1), 115-138. https://doi.org/10.3992/jgb.16.1.115

Tokyay, M., \& Özdemir, M. (1997). Specimen shape and size effect on the compressive strength of higher strength concrete. Cement and Concrete Research, 27(8), 1281-1289. https://doi.org/10.1016/S0008-8846(97)00104-X

TS EN 1097-6. (2013). Tests for mechanical and physical properties of aggregates- Part 6: Determination of particle density and water absorption. https://intweb.tse.org.tr/

TS EN 12350-2. (2010). Testing fresh concrete- Part 2: Slump test. https://intweb.tse.org.tr/

TS EN 14889-1. (2006). Fibres for concrete - Part 1: Steel fibres - Definitions, specifications and conformity. https://intweb.tse.org.tr/

TS EN 197-1. (2012). Cement- Part 1: Compositions and conformity criteria for common cements. https://www.scribd.com/

TS EN 206. (2014). Concrete- Part 1: Specification, performance, production and conformity. https://intweb.tse.org.tr/

Tuğal, M., \& Arıcı, E. (2011). Investıgate of sıze effect ın geometrıc changes of splıttıng tensıle strenght of concrete. E-Journal of New World Sciences Academy, 6(4), 1086-1092. https://dergipark.org.tr/Yi, S.-T., Yang, E.-I., \& Choi, J.-C. (2006). Effect of specimen sizes, specimen shapes, and placement directions on compressive strength of concrete. Nuclear Engineering and Design, $236(2)$, $115-127$. https://doi.org/10.1016/j.nucengdes.2005.08.004

Zeynal, E. (2008). The effect of steel fiber and w / c ratios on impact strength and mechanical properties of steel fiber concretes [Ege Univeristy]. https://tez.yok.gov.tr/

Zhang, Y., Li, H., Abdelhady, A., Yang, J., \& Wang, H. (2021). Effects of specimen shape and size on the permeability and mechanical properties of porous concrete. Construction and Building Materials, 266, 121074. https://doi.org/10.1016/j.conbuildmat.2020.121074 